\title{
VIDEOACTIVISMO ONLINE Y PROBLEMATIZACIÓN DEL CONCEPTO DE AUTORÍA. EL ANONIMATO EN EL COLECTIVO AUDIOVISUAL MALAGUISTÁN
}

\author{
ONLINE VIDEOACTIVISM AND PROBLEMATIZATION \\ OF CONCEPT OF AUTHORSHIP. THE ANONYMITY BY AN \\ AUDIOVISUAL PRODUCTION COLLECTIVE, MALAGUISTÁN
}

\author{
Jordi ALBERICH-PASCUAL \\ Universidad de Granada \\ jalberich@ugr.es
}

\section{Ana SEDEÑO-VALDELLÓS \\ Universidad de Málaga \\ valdellos@uma.es}

Resumen: El videoactivismo online es un reciente fenómeno audiovisual que permite que colectivos compuestos por ciudadanos alejados de la práctica institucional cinematográfica protagonicen y dirijan sus propios proyectos audiovisuales, con un componente transformador. El presente artículo analiza experiencias que siguen esta dirección y que tienen en el anonimato y en la falta de reconocimiento personal de la figura del autor, su principal razón de ser. Malaguistán denuncia la situación precaria de la infraestructura y de los espacios ciudadanos en la ciudad de Málaga, 
con piezas distribuidas por Internet de manera anónima, y con un tipo de lenguaje audiovisual específico que combina formas de narrativa cruda con un remontaje paródico basado en la ironía.

Palabras clave: Videoactivismo. Anonimato. Audiovisual crítico. Cine colectivo.

Abstract: Online videoactivism is a recent audiovisual formula that allows audiovisual groups, composed by citizens fair from institutional practice, to film their own audiovisual projects, sometimes characterized with a transforming social component. The paper analyzes some experiences that follow this direction: anonymity and lack of personal recognition in the figure of the filmmaker are the main features. Malaguistán complaints with pieces distributed by Internet, about the precarious situation of infrastructure and citizen space in Malaga and with an special kind of audiovisual language that combines ways of raw narrative with a parodic edition based on irony.

Key Words: Videoactivism. Anonymity. Critical Cinema. Collective Cinema.

1. INTRODUCCIÓN: PROBLEMATIZACION DE LA AUTORÍA Y ANONIMATO EN EL VIDEOACTIVISMO ONLINE CONTEMPORÁNEO

La iconosfera contemporánea se caracteriza por la diversidad extrema de sus propuestas. El cine mainstream, la integración transnacional de contenidos y plataformas, y el crecimiento exponencial de la experiencia de usuario en multitud de formatos audiovisuales se da en paralelo a una producción audiovisual activista, minoritaria, y horizontal en su generación. Un activismo audiovisual que no se puede entender ya sin su distribución 
online a través de la red.

La autoría como criterio nominal y exclusivo de calidad y producción de las obras artísticas y culturales ha dejado de ser central en la discusión y debate sobre las prácticas contemporáneas. Así la atención se ha desplazado hacia la obra así, hacia su contenido o discurso. Ello se encuentra en la línea coherente con las problematizaciones del yo y su viaje hacia el debate sobre un nosotros. En este sentido los abordajes sobre la función autor de Foucault (1999), Barthes (1987), Geertz (1989), Agamben (2009), Negri (2000) o Virno (2003) en la escena internacional, así como los trabajos previos sobre anonimato, ciudadanía y colectividad de López-Petit (2009), Delgado (2003), y Garcés (2007, 2009) en el ámbito nacional han constituido una reflexión contundente.

Preguntar por el nosotros no es preguntar por la comunidad frente a la sociedad, por lo público frente a lo privado o por lo colectivo frente a lo individual. El nosotros no es un ámbito de lo social, es una experiencia que transforma lo social. Es un proceso de subjetivación y de politización que implica inscribirse en el mundo desde la co-implicación (Garcés, 2009).

Otras reflexiones cercanas pueden encontrarse en numerosos trabajos como las investigaciones doctorales sobre prácticas de control de González-Díaz (2013), los estudios sobre activismo mediático de CandónMena (2012), Baillie-Smith (2013) y Cordero-Sánchez \& Alberich-Pascual (2015), así como las publicaciones e investigaciones previas sobre cine de resistencia y videoactivismo 2.0 de Sheppard (2005), Widgington (2005), Didi-Huberman (2008), o Vila-Alabo (2012), entre otras a destacar.

En el seno de un activismo mediático de resistencia individual y colectiva que caracteriza a un espacio cultural transnacional, el videoactivismo audiovisual de transformación social puede observarse desde variados escenarios o ámbitos: la concienciación, la creación comunitaria o la lucha de derechos sociales... 
El videoactivismo contemporáneo recoge del arte militante y del videoarte histórico algunos de los rasgos más importantes que señalan estas producciones, autodefiniéndose a su vez como una práctica con vocación de transformación desde la producción horizontal, la disolución de la autoría clásica y/o asunción de nuevas fórmulas de adscripción de la responsabilidad de la creación audiovisual. Si en los orígenes del cine de protesta, político y militante parte de la producción optó por el anonimato como una forma de producción colectiva que permitía cierta seguridad frente a represalias de los grupos políticos hegemónicos y/o los gobiernos, la producción videoactivista actual elige el anonimato con otros fines. En este caso, como ya se ha revisado en otros trabajos (Mateos y Sedeño, 2015) supone una forma más de colectivización de la figura de responsabilidad en el videoactivismo (junto al autor común, el sin-autor, el crowd y otros), ni mucho menos la mayoritaria, que pretende subrayar la parte final de la ecuación comunicativa, dejando mayor protagonismo al espectador/receptor y apelando a su rol activo. Además, el contexto del pensamiento contemporáneo sobre la subjetividad, el trabajo artístico como performativo y un especial acento desde la estética de la recepción en el autor y en el ocaso de su necesidad, han aportado una última capa de contexto propicio para variadas manifestaciones, también para las de producción audiovisual colaborativa o videoactivista. A esto se suma un hábitat tecnológico, espacio opaco de control que, aunque hace compleja la desaparición de las huellas de autoría de cualquier manifestación (textual, visual, sonora...), permite un cierto grado de privacidad y opcionalidad según las plataformas y el nivel de pericia técnica en su configuración. Esta es de las habilidades específicas del flamante prosumidor mediático.

Sin embargo, si es necesaria cierta reflexión sobre el enmarque de una subjetividad anónima presente en el panorama de creación, vinculado a lo político, contemporáneo. Aunque no es momento aquí de desarrollar el debate sobre la naturaleza política de cualquier manifestación audiovisual, de acuerdo con Agamben (2009), la teoría del Bloom de Tiquun comienza con la disolución de la subjetividad del sujeto contemporáneo. También 
el ámbito de los estudios visuales y de la reflexión de la teoría crítica, con autores como Freedberg (2009) o Comolli (2009), han descrito y/o propuesto modos alternativos de creación comprometida desde el arte y la creación visual, con los que la imagen alcance a convertirse en una herramienta con la que pensar y proponer otras realidades sociales y políticas alternativas a las existentes/hegemónicas.

En afinidad con ello, en el videoactivismo contemporáneo se desarrollan un conjunto de estrategias y prácticas discursivas de creación y producción audiovisual tendentes a la colectivización y a una problematización de la función autor, caracterizadas habitualmente por generar "un proceso de vídeo sin guion, dirigido por las bases, que se mueve hacia adelante en ciclos iterativos de grabación y revisión del material. (...) Los participantes toman parte en momentos o en todo el proceso de rodaje, guionización o selección del contenido" (Johansson, 1999: 21-23).

Así, en oposición a la conceptualización dominante del director/ realizador como autor único de una obra audiovisual que ejerce el control completo (para algunos psicológico) sobre todos los procesos de invención colectiva de una película (Mitry, 1988), el videoactivismo se caracteriza por una problematización consciente de esta figura de orden estético, y opone la necesidad de una práctica fílmica comprometida, que se desnude de esta invisibilidad lingüística y haga consciente al espectador de su estrategia y capacidad de generación discursiva. Eliminando la figura de liderazgo que supone el director en el cine tradicional, la pérdida de la función autor se concibe como un poder generador de contenido audiovisual que delega sus funciones en la colectividad de un grupo humano.

Esta problematización de la autoría es compartida por muchas prácticas de cine etnográfico o antropológico que no tenemos espacio para analizar completamente aquí. En concreto, el anonimato, como práctica extrema de la sinautoría, ha sido posible por las condiciones vitales de la modernidad en los centros urbanos. El viraje contemplativo del deambular contemporáneo ha sido teorizado por George Simmel, Emil Durkheim o Erwin Goffman. De acuerdo con Manuel Delgado (2003), 
el anonimato es un requisito de la ciudadanía ejercida en los espacios públicos, especialmente en la calle. Cuando ese espacio es Internet, retoma su fuerza gracias a la capacidad de convocatoria para movilizaciones y da respuesta a una necesidad de construcción de identidad colectiva frente al poder. Movimientos como el $15 \mathrm{M}$ o Yo soy 132, concuerdan con esta idea de convocatoria abierta, conjunción ciudadana, asamblearismo y organización horizontal que permite diversas posibilidades de autoposición en el anonimato: la falta de identificación, la contraidentificación, que es un presencializarse oponiéndose, o la desidentificación, que es un presencializarse ocultándose (López-Petit, 2009). Todos estos movimientos se posicionan en alguna de estas micromodalidades.

La característica básica del anonimato es la impersonalidad, y en ella el momento actual permite nuevas fórmulas de impunidad en el comportamiento gracias a las redes sociales. Tras una máscara en forma de nick, avatar o perfiles inciertos o equívocos, el individuo se irresponsabiliza de todo un sin fin de acciones impropias y, por tanto, de su peso en la conciencia moral. Sin embargo, también permite un discurso que impreca por la mejora de las condiciones globales de vida en los núcleos urbanos, en una operación que pone el foco en el discurso y esconde la personalidad que está detrás de él.

Si la función autor era dibujada por Foucault (1999: 329-360), como característica del siglo XIX, su supresión abre el audiovisual a nuevas formas de representación experimentales que han sido "tomadas" por los colectivos de videoactivismo. Es en el seno de estos procesos de naturaleza colectiva donde adquiere fuerza la escritura de una gramática de la multitud, término desarrollado por Paolo Virno a partir de Arte y Multitud de Negri (2000), que da cuenta del surgimiento de modalidades de entrelazar lo político, lo cultural y lo económico, tal y como se ejemplifica en la emergencia de una larga serie de colectivos de investigación-acción recientes con voluntad transformadora como Video nas Aldeias, Cinemaabierto, Subtramas, Cine sin Autor (CsA) y Malaguistán. Los colectivos, grupos sociales o comunidades de activismo videográfico contemporáneo con objetivos de 
transformación social y su generación de modelos alternativos de pensar los agentes de producción/realización en torno a temáticas cotidianas, han sido analizados ya en textos recientes de especialización sobre la autoría audiovisual. Tal y como los estudios precedentes de Mateos y Sedeño (2015), Montero y Moreno (2014), Mateos y Lanchares (2014) han evidenciado con Cine sin Autor, Cinemaabierto y otros, se caracterizan por la llamada narrativa cruda o raw narrative, una forma prototípica del audiovisual con objetivo de documentar situaciones para denunciarlas, con una pretensión de máxima objetividad. También Hito Steyerl habla de imagen pobre como "imágenes populares -imágenes que se pueden hacer y ver por los muchos- que expresan todas las contradicciones de la multitud contemporánea (...) su permanente disposición para la transgresión y la presentación simultánea" (Steyerl, 2009), lo que vincula la producción con la función de distribución online y viral de las imágenes.

Con este tipo de forma de la expresión de los mensajes audiovisuales, los colectivos de vídeo pretenden eliminar cualquier fórmula de naturaleza estilística que permita identificarles, en una especie de forma narrativa de grado 0 . ¿Existen renovadas gramáticas/lenguajes fílmicos o audiovisuales construidos desde el anonimato?

Para realizar un aporte teórico-práctico a esta línea académica comenzada hace algunos años, el presente artículo tiene como objetivo específico analizar vídeos de Malaguistán, colectivo audiovisual videoactivista que distribuye sus vídeos online de manera anónima, para caracterizarlos desde un punto de vista audiovisual.

\section{MÉTODOS Y MATERIALES}

Aun cuando nuestro abordaje parte de una perspectiva global, hemos focalizado nuestra investigación en el estudio de un colectivo de videoactivismo online surgido en el ámbito español a nivel local, Malaguistán, con el análisis de sus vídeos, en los que el anonimato ha tenido un papel determinante. 
Nuestro estudio se ha estructurado a partir de una aproximación de lo general a lo particular a través de una metodología de investigación de tipo cualitativa. Tras una primera fase de investigación basada en la búsqueda documental y una revisión bibliográfica, se ha procedido al análisis textual, en una segunda fase. En esta etapa se trata de establecer una especie de descripción de las características del lenguaje audiovisual de los vídeos de este colectivo, como perteneciente a este grupo de propuestas audiovisuales de representación desde el anonimato.

En este se han observado con atención los siguientes criterios: lenguaje audiovisual (tipología de planos, movimientos de cámara, angulación), sonido analógico y verbal (uso de la voz, el silencio, los diálogos, relación imagen/música), música (diegética/extradiegética, original, versiones, función respecto a la imagen), articulación espaciotemporal, textos escritos (número, ubicación, relación con imagen), personajes (¿quiénes son?, número), uso de imagen documental (tomada de qué eventos, préstamos de videos anteriores...).

Como complemento se ha realizado una entrevista en profundidad a partir de un cuestionario a un miembro del colectivo Malaguistán ${ }^{1}$ (Málaga, 29 de septiembre de 2014). Por esta opción del anonimato, se hace problemático el estudio académico de caso: únicamente hemos tenido acceso a uno de sus miembros, David, y, por tanto, nula oportunidad de contrastar versiones con otros componentes, lo que supone un obstáculo para la investigación. Algunas de las ideas que han guiado las conversaciones han sido las condiciones y objetivos con los que se desarrolla el trabajo y los procesos y financiación genérica con que se mantiene el proyecto y se incardinan y editan los vídeos. La entrevista tuvo como objetivo contextualizar la investigación de manera general, y será empleada sólo de manera lateral para describir objetivos o formas de producción, y como ampliación del análisis audiovisual o textual.

\footnotetext{
${ }^{1}$ Cuyo nombre es David (Málaga, 29 de septiembre de 2014).
} 


\section{ESTUDIO DE CASO: COLECTIVO MALAGUISTÁN}

Los orígenes del vídeo colectivo en Málaga se remontan a las acciones y performances del grupo Agustín Pareja School, surgido en los años ochenta en la capital de la Costa del Sol y ocupado en variadas prácticas interdisciplinares que iban desde el vídeo y el cartel, hasta la instalación y el arte de acción. Los vídeos de Malaguistán retoman este carácter de búsqueda de valores de mejora de la ciudad desde un posicionamiento del anonimato como elemento que diluye la autoría o identificación del componente personal o artístico.

Malaguistán surge en 2011 en el barrio de Lagunillas (cercano al centro histórico puede considerarse parte de él) con el objetivo de realizar una propuesta crítica en vídeo, empleando un lenguaje (habla coloquial, formas de comportamiento) propio del contexto geográfico de la ciudad, para visibilizar las problemáticas que la atañen. Como manifestación cultural y por sus características no resulta ajena al contexto post-15 $\mathrm{m}$ y a todo su imaginario colectivo que prioriza la creación de redes de colaboración a nivel local y la producción audiovisual como herramienta transformadora, bajo la utopía del poder revelador de la imagen en toda la creación alternativa de los últimos años.

Con un discurso directo, que debe mucho a la estética documental, pretende denunciar desafíos continuados y no resueltos de la capital malagueña, en relación a temáticas como infraestructura urbanística, playas, fiestas y eventos culturales dándoles un sentido centrado en la idiosincrasia de sus habitantes.

Cuando se les pregunta directamente por la opción del anonimato (en su canal de YouTube no existe ninguna información de nombres, direcciones) se dice "Hablamos de que no importa quien lo haga (...) si fuese otro tipo de producto más serio, quizá tiene más sentido (...) pero esto no es importante quien lo haga"2. Ese acento sobre el objetivo de los vídeos, resulta una forma de desidentificación (Lopez Petit, 2009: 32), tal

${ }^{2}$ Entrevista con Malaguistán (29 de septiembre de 2014). 
como es definida anteriormente.

Los vídeos (28) se han desarrollado a lo largo de tres temporadas, que se han caracterizado por una importante evolución técnica y mejora en la resolución en la grabación del registro de imágenes. En la primera temporada (2011), el listado de piezas generadas es el siguiente: Malaguistán3; Las Calles; La playa; Parque Bélico; El plan E; Parque Natural; Las luces; Bis. El presupuesto; La cofradía.

Cuando se le pregunta por el comienzo de la actividad y cómo plantearon el trabajo inicial, declara: "en principio, consultábamos el periódico los fines de semana, donde siempre había noticias de corrupción, de problemas urbanísticos... e intentábamos escribir una pequeña historia o guion ejemplificada cerca de Lagunillas, el barrio, con la que denunciar la dejadez de los políticos locales. Ello se convirtió en una dinámica con la que hacíamos un breve vídeo cada dos semanas"4.

Como corresponde a lo que podríamos denominar una fase primera de aprendizaje de las técnicas y posibilidades del lenguaje audiovisual por parte de sus componentes y junto a la aún no tan usual tecnología digital de buena calidad de imagen), estos trabajos se caracterizan por su brevedad, su inmediatez en el uso de la cámara y los recursos del montaje y la música, y el empleo de textos para complementar unos mensajes críticos y directos: un discurso basado en un lenguaje de realización crudo, restado de lo artificioso o sofisticado y alejado de recursos visuales avanzados.

El capítulo Las calles resulta significativo como ejemplo del modo de realización del videoactivismo del colectivo. En él, los textos recontextualizan el contenido de la banda visual y, con la ayuda del componente sonoro musical y su función estructurante, construyen una pieza repleta de fórmulas que problematizan la ciudad a través del juego con los nombres de las calles: la dejadez de las infraestructuras básicas de ciertas zonas de la ciudad es empleada con técnicas de ironía y antítesos.

\footnotetext{
${ }^{3}$ https://www.youtube.com/watch? $v=$ paTpqnlVjnI [19/06/2018]. Incluimos el link para que puedan consultarse los vídeos de este colectivo a partir de aquí.

${ }^{4}$ Entrevista con Malaguistán (29 de septiembre de 2014).
} 
Ello se explicita a través de la muestra sumativa de planos de las trece placas con que se nombra una corta calle (Cobertizo del Conde): tal despliegue contrasta con la dejadez de cuidados de sus calles y fachadas, que no se arreglan para fomentar la especulación urbanística (como poco tiempo después se ha comprobado).
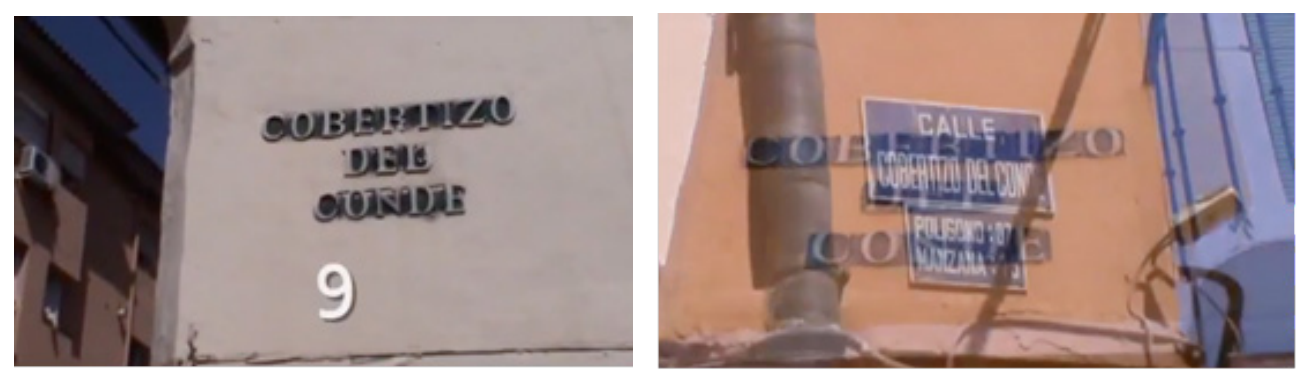

Figura 1. Dos capturas de pantalla del vídeo Las calles

(Malaguistán, 1. ${ }^{\mathrm{a}}$ temporada).

La ironía resulta un recurso global de todos los videos de esta temporada. Entendemos que su función es establecer un vínculo de sentido con el espectador. En el caso de Las luces, se editan diversos planos de pertrechas cajas de electricidad en diversas calles de la ciudad junto a un diálogo ficticio de dos electricistas. La conversación sugerida se pone en voz de un supuesto técnico electricista con un acento especialmente exagerado, por lo que se escriben los textos para que el espectador no avezado pueda seguir el discurso, aunque en otro registro de habla más culto. Esta coincidencia sonora, visual y textual tiene un efecto dramático y espacial importante y su importancia en la exposición sincrónica del mensaje, donde el contenido y la expresión se encuentran en contradicción. Esta contraposición de elementos causa este efecto irónico... Como se dice, "al final da igual": Malaguistán pretende reactivar una visión crítica sobre la idiosincrasia de la ciudad.

La segunda temporada (2013-2014) se desarrolla entre otras temáticas y apunta a un mejoramiento de las condiciones de producción, 
coincidiendo con la llegada masiva y abaratamiento de las tecnologías de grabación digital y su accesibilidad entre los usuarios amateurs de vídeo. El colectivo continúa con su carácter de agitación empleando los asuntos de la ciudad, sus fiestas, su carácter turístico y algunos proyectos desarrollados de naturaleza urbanística o arquitectónica: El Muro II; Los farolillos; La caseta; Megaconstrucciones; Los postes de la Smart City; Los graffitis; La Semana Santa eterna; La alfombra; La cofradía.

En Los postes de la Smart City el colectivo critica cómo se vende una imagen de la ciudad ligada a la innovación y la eficiencia energética. El vídeo comienza con imágenes cedidas del programa "Informe Semanal" donde se emitió un reportaje sobre el asunto. El texto en voz en off es el siguiente: "En ese sentido Málaga es el proyecto español pionero en una ciudad ecoeficiente que empezó a desarrollarse hace cuatro años en el barrio de la Misericordia, liderado por varias empresas y centros de investigación. $\mathrm{Su}$ objeto es conseguir integrar con fuentes renovables de energía a la red electrónica. Se trata de acercar la generación con el consumo y que lo que no se gaste se almacene en baterías que permitan utilizar esa energía por ejemplo en alumbrado público telegestionado o en el uso de vehículos eléctricos". Seguidamente, el alcalde de la ciudad, Francisco de la Torre, aparece en imagen explicando algunos detalles del proyecto. Tras unos 15-20 segundos se incluyen imágenes de postes derruidos, cajas eléctricas abiertas y en ruinas, de las que hay innumerables en la ciudad (Figura 2). El recurso al contrapunto audiovisual permite comprobar el despropósito de la utilización política de las palabras y las temáticas de la eficiencia energética y la ciudad futura mientras se observan la recopilación de farolas, cables y enganches eléctricos del siglo XIX).

Tras un nuevo speech en voz en off en el que se vuelve a incluir el contenido directo del programa de Televisión Española, se pasa a una nueva entrevista, esta vez con Jaime Briales, Director de la Agencia de la Energía de Málaga. Tras unos segundos, la banda imagen es intervenida y comienza a mostrar planos explícitos de la mala situación de estas instalaciones. Mientras continúa la voz en off: “Al final no se trata de que 
la ciudad sea más inteligente, la ciudad es un ente abstracto que no es más inteligente o no... Al final de lo que se trata es de que los ciudadanos seamos inteligentes o de que tengamos opción a ser inteligentes" dice un entrevistado. Parece esta la triste conclusión que denuncia el vídeo: la imposibilidad de que esto pueda ocurrir ante la manipulación a la que la ciudadanía es sometida.
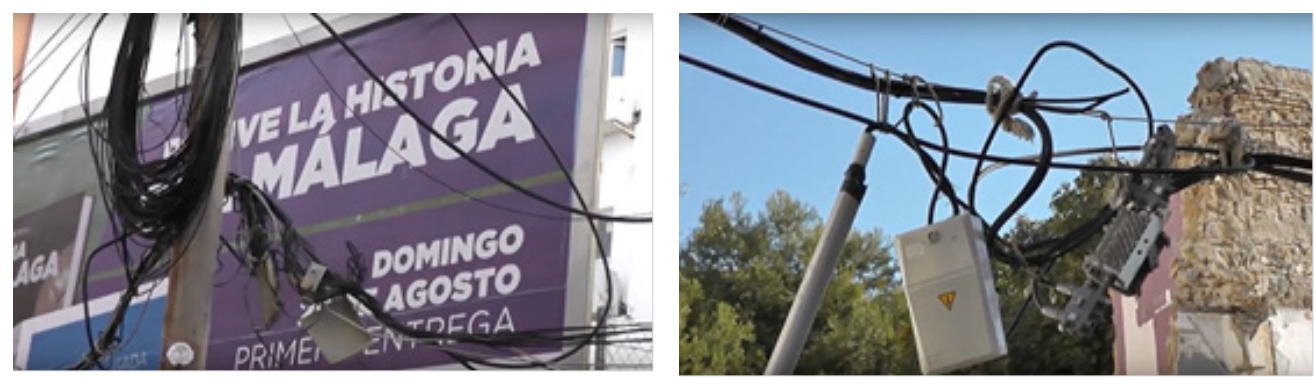

Figura 2. Dos capturas de pantalla de Los postes de la Smartcity (Malaguistán, 2. ${ }^{\text {a }}$ temporada).

En la tercera temporada (2015), Malaguistán acude a temas políticos directos o relacionados con los dirigentes de la ciudad. Se compone de cuatro únicos vídeos de la temporada: El proyecto definitivo de los Baños del Carmen; El proyecto definitivo VII; La Legislatura 2011-2015; La feria 2015.

Las piezas se estructuran según dos modalidades. Por un lado, El proyecto definitivo VII y La feria 2015 pertenecen a la categoría de remix en la que se practica la remezcla de programas y secuencias de películas anteriores. En el primer caso, se reedita un informativo estadounidense, doblándose la voz del presentador: a modo de noticia se describen los últimos acontecimientos en torno al proyecto definitivo de los Baños del Carmen, un conocido restaurante, lugar de ocio glorioso y balneario de la ciudad en las primeras décadas del siglo XX.

En La legislatura 2011-2015 se hace un repaso de estos años de Alcaldía de Francisco de la Torre, a ritmo de meme musical del conocido tema "Paco, Pacó", con frases como esta "Y roban como nadie, 
Pacó" junto a imágenes sobre "logros" de la alcaldía en el período: el Centro Pompidou, el Museo Ruso (Tabacalera), el metro... Todos han dejado innumerables problemas y dudas sobre corrupción respecto a su construcción, adjudicaciones y gestión. Los demás partidos políticos no quedan fuera de la mirada crítica (Figura 3).
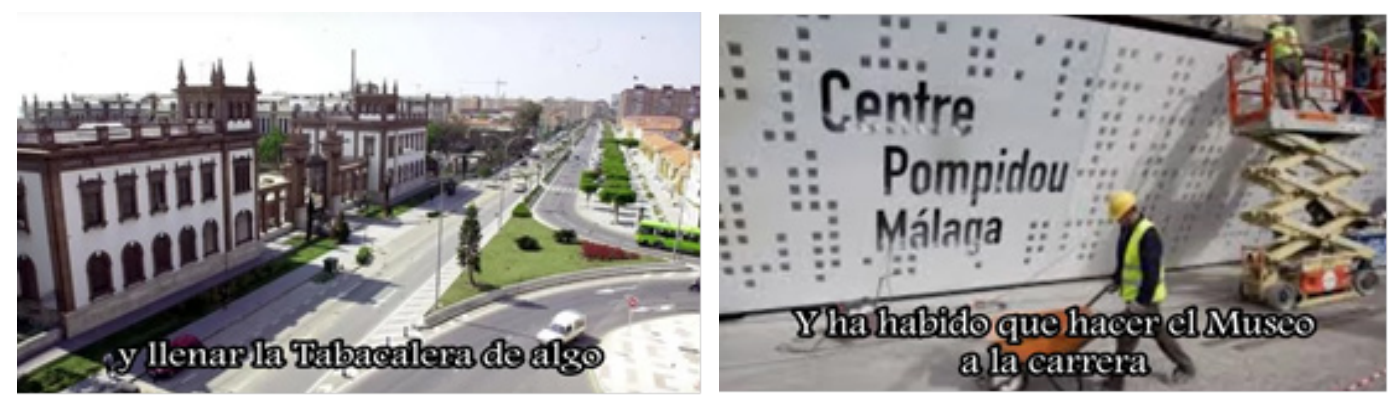

Figura 3. Dos capturas de pantalla del video La legislatura 2011-2015 (Malaguistán, 3. ${ }^{a}$ temporada).

En el caso de La feria 2015 se utiliza la conocida escena de locura final de El Hundimiento (Alemania, 2006), fuente de muchos memes y mashups en Internet. En concreto esta pieza ha dado lugar a unos 100 vídeos y ha originado polémica con su productora Constantine films. Los mashups de remontaje de imágenes y sonidos de vídeos con material histórico o político o de películas de este género tienen un alto poder evocador y gran capacidad viral y permiten "proporcionar un espacio en el que los viejos y los nuevos vídeos que levantan preocupaciones políticas similares, son presentados al espectador en un red intertextual que puede potencialmente conectar las luchas pasadas con las presentes" (Askanius, 2013: 8). Esto supone una intertextualidad de naturaleza paródica que Malaguistán emplea en todo momento como colectivo videoactivista anónimo, uniendo temáticas tan encontradas como el genocidio judío o la feria de Málaga de 2015. 


\section{CONCLUSIONES}

El videoactivismo contemporáneo problematiza numerosos conceptos y modelos tradicionales que formaban parte del paradigma clásico del audiovisual, o Modo de Representación Institucional (MRI), como digno sucesor del cine militante y de multitud de prácticas de cine documental o testimonial. De su seno emergen una diversidad de prácticas de ruptura que, desde la perspectiva de la comunicación alternativa, establecen puentes entre las necesidades de colectivos en situación precaria o marginalizados y su visibilización y legitimación social de su acción.

Estas prácticas audiovisuales de ruptura se caracterizan por unas elecciones audiovisuales problematizadoras de conceptos tan centrales como el de la autoría o atribución personal de la responsabilidad creativa, a través de la ironía o la subversión de códigos relacionados con el montaje, el guion o la interpretación actoral. Todas estas estrategias empoderan al lenguaje audiovisual con elementos para la de-construcción crítica de los discursos audiovisuales institucionales, así como para la construcción alternativa de un imaginario audiovisual propio.

El colectivo Malaguistán construye su capacidad de subversión en mensajes audiovisuales que tratan la realidad local de una manera creativa: son anónimos, no subrayados personalmente y apelan a la complicidad colectiva del espectador a través de la ironía. En este sentido, parece que se apartan de una estricta imagen pobre. Su empleo de la parodia los aleja de manera nítida de esa narrativa cruda que parece caracterizar a otros colectivos de anonimato audiovisual, aunque se sitúa en la línea de la tradición del mashup y el gusto por el remontaje y el juego en postproducción que se encuentra en el audiovisual colectivo que se desarrolla en la red.

El videoactivismo online representado por el colectivo Malaguistán genera estrategias de transformación social con un lenguaje audiovisual que se encuentra en la esfera de otros colectivos de sinautoría y anonimato fílmico, aunque adaptándolos a temas y enfoques locales y generando prácticas más complejas de postproducción (parodia, ironía...), que enlazan 
con las nuevas condiciones de distribución y apelación al espectador. Esto nos hace pensar en ellos como nuevos actores comunicativos de plena significación en la caracterización de la escena contemporánea. Esperamos haber contribuido con ello a la construcción de parte del mapa actual del pensamiento crítico a través de la imagen y el audiovisual, aunque su completa descripción se encuentra en permanente revisión, debido al surgimiento repetido de colectivos y la continua actualización de sus propuestas.

\section{REFERENCIAS BIBLIOGRÁFICAS}

AGAMBEN, G. (2009). A propósito de Tiqqun. Presentación del libro Contribution a la guerre en cours. Paris: La fabrique.

ASKANIUS, T. (2013). "Online video activism and political mash-genres". Jomec Journal 4 (también en http://doi.org/10.18573/j.2013.10257 [21/04/2018]).

BAILLIE SMITH, M. (2013). “The changing development landscape and new development paradigms: the end of development education or a chance to find its voice?" [Powerpoint slides]. Opening address to the conference Global justice through global citizenship: the role of global education and public awareness. Bruselas, 20-21 de noviembre.

BARTHES, R. (1987). "La muerte del autor”. En El susurro del lenguaje. Más allá de la palabra y la escritura, R. Barthes, 175-198. Barcelona: Paidós Comunicación.

BOURDIEU, P. (2002). Pensamiento y acción. Buenos Aires: Libros del Zorzal.

CANDÓN-MENA, J.(2012). "Soberanía tecnológica en la era de las redes". Revista internacional de pensamiento político 7, 73-92 (también en http://pensamientopolitico.org/Descargas/RIPP07073092.pdf [21/04/2018]). 
COMOLLI, J.L. (2009). "Malas compañías: documento y espectáculo". Cuadernos de cine documental 3, 76-89.

CORDERO-SANCHEZ, I. y ALBERICH-PASCUAL, J. (2015). "Revisión de usos sociales y formas de ejercer la política”. El profesional de la información 24.6, 811-818.

DELGADO, M. (2003). “Anonimato y ciudadanía. Derecho a la indiferencia en contextos urbanos”. En Inmigración y cultura, M. Delgado Ruiz (ed.), 9-21. Barcelona: Centro de Cultura Contemporánea de Barcelona.

DIDI-HUBERMAN, G. (2010). "Las imágenes son un espacio de lucha. Entrevista con Amador Fernández-Savater". Diario Público. http:// blogs.publico.es/fueradelugar/183/las-imagenes-son-un-espaciode-lucha [21-04-2018].

FOUCAULT, M. (1999). “QQué es un autor?”. En Entre filosofía y Literatura. Obras esenciales, M. Foucault, 329-360 [1. a ed. 1985]. Barcelona: Paidós.

FREEDBERG, D. (2009). El poder de las imágenes. Estudios sobre la historia y la teoría de la respuesta. Madrid: Cátedra.

GARCÉS, M. (2007). “La experiencia del nosotros”. Zehar 60-61. Número especial "La escuela abierta", 44-48 (también en http://blogs.llull. cat/venezia2009/? $p=1229$ ).

(2009). "Un mundo entre nosotros". Revista d'Espai en Blanc 5-6. http://espaienblanc.net/?page_id=759 [21-04-2018].

GEERTZ, C. (1989). El antropólogo como autor. Barcelona: Paidós.

JOHANSSON, L. (1999). "Participatory Video and PRA: Acknowledging the politics of Empowerment". Forests, Trees and People 40/41, 21-23.

LÓPEZ PETIT, S. (2009). "Los espacios del anonimato: una apuesta por el que querer vivir". Espai en Blanc 5-6 (también en http:// espaienblanc.net/?page_id=749 [21-04-2018]).

MATEOS, C. y LANCHARES, L. (2014). "Languages of Video-Activism". Video Activism Workshop en Bristol Radical Film Festival, 3-9 de 
marzo.

MATEOS, C. y SEDEÑO, A. (2015). "Videoactivismo y autoría colectiva". En Videoactivismo y movimientos sociales Teoría y praxis de las multitudes conectadas, F. Sierra y D. Sierra (eds.), 298-331. Barcelona: Gedisa / CIESPAL.

MITRY, J. (1988). Estética y psicología del cine. 1. Las estructuras. Madrid: Siglo XXI.

MONTERO, D. y MORENO, J.M. (2014). El cambio social a través de las imágenes: guía para entender y utilizar el video participativo. Madrid: Catarata.

NEGRI, T. (2000). Arte y multitud. Barcelona: Trotta.

PRESENCE, S. (2014). "The Contemporary Landscape of Video-Activism in Britain". En Marx and Moving Images of Activism, E. Mazierska \& L. Kristensen (eds.), 186-212. Oxford and New York: Berghahn. SEDEÑO, A. (2013). "Cine sin autor como pedagogía crítica audiovisual: bases teóricas, antecedentes y postura crítica". Communication papers: media literpacy and gender studies 2, 91-97 (también en https://dugi-doc.udg.edu//bitstream/handle/10256/8781/ Article9-p91.pdf? sequence $=1$ [21/04/2018]).

SHEPPARD, M. (2005). "Cine y resistencia". Cuadernos del centro de estudios en diseño y comunicación 18 (también en fido.palermo. edu/servicios_dyc/publicacionesdc/archivos/105-libros.pdf [21/04/2018]).

STEYERL, H. (2009). "In defense of the poor image". e-flux 10, https:// www.e-flux.com/journal/10/61362/in-defense-of-the-poorimage/\#_ftnref9 [15-04-2018].

VILA-ALABO, N. (2012). "Videoactivismo 2.0: ¿revueltas, producción audiovisual y cultura libre?". Toma Uno 1, 167-176 (también en https://revistas.unc.edu.ar/index.php/tomal/article/ viewFile/8578/9443 [21/04/2018]).

VIRNO, P. (2003). Gramática de la multitud. Para un análisis de las formas de vida contemporáneas. Madrid: Traficantes de sueños. 
VIDEOACTIVISMO ONLINE Y PROBLEMATIZACIÓN DEL CONCEPTO DE AUTORÍA. El anONimato EN El COLECTIVO AUdiovisual MaLaguistán

WIDGINGTON, D. (2005). "Screening revolution. FAQS about video activism". En Autonomous Media. Activating Resistance \& Dissent, A. Langlois y F. Dubois. (eds.), 103-121. Montreal: Cumulus Press.

Recibido el 29 de abril de 2018.

Aceptado el 3 de septiembre de 2018. 
